\section{References and Notes}

1. WHO, "Global Polio Eradication Initiative: 2004 Annual report" (WHO/VB/05.05, WHO UNICEF, IVB Document Centre, Geneva, 2005) (http://whqlibdoc.who.int/hq/ 2005/WHO_POLIO_05.03.pdf).

2. Funding update (www.polioeradication.org/fundingbackground.asp).

3. F. Fenner, D. A. Henderson, I. Arita, Z. Jezek, I. D. Ladnyi, Smallpox and Its Eradication (WHO, Geneva, 1988).

4. R. B. Aylward, R. W. Sutter, D. L. Heymann, Science 310, 625 (2005).

5. O. M. Kew, R. W. Sutter, E. M. de Gourville, W. R. Dowdle, M. A. Pallansch, Annu. Rev. Microbiol. 59, 587 (2005).

6. A. Nomoto, I. Arita, Nat. Immunol. 3, 205 (2002).
7. M. Arita, et al., J. Virol. 79, 12650 (2005)

8. J. D. Sachs, in The End of Poverty: Economic Possibilities for Our Time (Penguin, New York, 2005), chap. 10.

9. WHO [press release] (www.who.int/mediacentre/ news/releases/2005/pr49/en/index.html).

10. "Can infectious diseases be eradicated? A report on the International Conference on the Eradication of Infectious Diseases," Rev. Infect. Dis. 4 (5), 916 (1982).

11. I. Arita, in The Eradication of Infectious Diseases, W. R. Dowdle, D. R. Hopkins, Eds. (Wiley, New York, 1998), chap. 15.

12. The World Bank, World Development Indicators 2004 (World Bank, Washington DC, 2004).

13. "Finance and economics: Recasting the case for aid."
Economist, 22 January 2005, p. 67

14. D. E. Bloom, D. Canning, M. Weston, World Econ. 6 (3) $15(2005)$

15. D. L. Heymann, R. W. Sutter, R. B. Aylward, Nature 434 699 (2005).

16. WHO, UNICEF, "GIVS global immunization vision and strategy 2006-2015" (WHO/VB/05.05, WHO UNICEF, IVB Document Centre, Geneva, 2005; (www.who.int/ vaccines/GIVS/english/english.htm).

17. We are grateful for the advice from D. A. Henderson, T. Miyamura, and T. Nakano.

10.1126/science.1124959

\title{
Who Should Get Influenza Vaccine When Not All Can?
}

\author{
Ezekiel J. Emanuel* and Alan Wertheimer
}

$\mathrm{T}$ he potential threat of pandemic influenza is staggering: 1.9 million deaths, 90 million people sick, and nearly 10 million people hospitalized, with almost 1.5 million requiring intensive-care units (ICUs) in the United States (1). The National Vaccine Advisory Committee (NVAC) and the Advisory Committee on Immunization Policy (ACIP) have jointly recommended a prioritization scheme that places vaccine workers, health-care providers, and the ill elderly at the top, and healthy people aged 2 to 64 at the very bottom, even under embalmers (1) (see table on page 855). The primary goal informing the recommendation was to "decrease health impacts including severe morbidity and death"; a secondary goal was minimizing societal and economic impacts (1). As the NVAC and ACIP acknowledge, such important policy decisions require broad national discussion. In this spirit, we believe an alternative ethical framework should be considered.

\section{The Inescapability of Rationing}

Because of current uncertainty of its value, only "a limited amount of avian influenza A (H5N1) vaccine is being stockpiled" (1). Furthermore, it will take at least 4 months from identification of a candidate vaccine strain until production of the very first vaccine (1). At present, there are few production facilities worldwide that make influenza vaccine, and only one completely in the USA. Global capacity for influenza vaccine

Department of Clinical Bioethics, The Clinical Center, National Institutes of Health, Bethesda, MD 20892-1156, USA.

The opinions expressed are the authors' and do not reflect the policies of the National Institutes of Health, the Public Health Service, or the Department of Health and Human Services.

*Author for correspondence. E-mail: eemanuel@nih.gov production is just 425 million doses per annum, if all available factories would run at full capacity after a vaccine was developed. Under currently existing capabilities for manufacturing vaccine, it is likely that more than $90 \%$ of the U.S. population will not be vaccinated in the first year (1). Distributing the limited supply will require determining priority groups.

Who will be at highest risk? Our experience with three influenza pandemics presents a complex picture. The mortality profile of a future pandemic could be U-shaped, as it was in the mild-to-moderate pandemics of 1957 and 1968 and interpandemic influenza seasons, in which the very young and the old are at highest risk. Or, the mortality profile could be an attenuated W shape, as it was during the devastating 1918 pandemic, in which the highest risk occurred among people between 20 and 40 years of age, while the elderly were not at high excess risk $(2,3)$. Even during pandemics, the elderly appear to be at no higher risk than during interpandemic influenza seasons (4).

Clear ethical justification for vaccine priorities is essential to the acceptability of the priority ranking and any modifications during the pandemic. With limited vaccine supply, uncertainty over who will be at highest risk of infection and complications, and questions about which historic pandemic experience is most applicable, society faces a fundamental ethical dilemma: Who should get the vaccine first?

\section{The NVAC and ACIP Priority Rankings}

Many potential ethical principles for rationing health care have been proposed. "Save the most lives" is commonly used in emergencies, such as burning buildings, although "women and children first" played a role on the Titanic. "First come, first served" operates in other emergencies and in ICUs when admitted patients retain
Rather than thinking only about saving the most lives when considering vaccine rationing strategies, a better approach would be to maximize individuals' life span and opportunity to reach life goals. beds despite the presentation of another patient who is equally or even more sick; "Save the most quality life years" is central to cost-effectiveness rationing. "Save the worst-off" plays a role in allocating organs for transplantation. "Reciprocity" - giving priority to people willing to donate their own organs - has been proposed. "Save those most likely to fully recover" guided priorities for giving penicillin to soldiers with syphilis in World War II. Save those "instrumental in making society flourish" through economic productivity or by "contributing to the well-being of others" has been proposed by Murray and others $(5,6)$.

The save-the-most-lives principle was invoked by NVAC and ACIP. It justifies giving top priority to workers engaged in vaccine production and distribution and health-care workers. They get higher priority not because they are intrinsically more valuable people or of greater "social worth," but because giving them first priority ensures that maximal life-saving vaccine is produced and so that health care is provided to the sick (7). Consequently, it values all human life equally, giving every person equal consideration in who gets priority regardless of age, disability, social class, or employment (7). After these groups, the save-the-mostlives principle justifies priority for those predicted to be at highest risk of hospitalization and dying. We disagree with this prioritization.

\section{Life-Cycle Principle}

The save-the-most-lives principle may be justified in some emergencies when decision urgency makes it infeasible to deliberate about priority rankings and impractical to categorize individuals into priority groups. We believe that a life-cycle allocation principle (see table on page 855 ) based on the idea that each person should have an opportunity to live through all 


\section{Priorities for Distribution of Influenza Vaccine}

1 Vaccine production and distribution workers Frontline health-care workers

People 6 months to 64 years old with $\geq 2$ high-risk conditions or history of hospitalization for pneumonia or influenza Pregnant women

Household contacts of severely immunocompromised People Household contacts of children $\leq 6$ months of age Public health and emergency response workers Key government leaders

Vaccine production and distribution workers

Frontline health-care workers
Vaccine production and distribution workers Frontline health-care workers
2 Healthy people $\geq 65$ years old People 6 months to 64 years old with 1 or more high-risk conditions

Healthy children 6 months to 23 months old Other public health workers, emergency responders, public safety workers (police and fire), utility workers, transportation workers, telecommunications and IT workers
Healthy 6-month-olds Healthy 1 -year-olds Healthy 2-year-olds Healthy 3-year-olds etc.
People 13 to 40 years old with $<2$ high-risk conditions, with priority to key government leaders; public health, military, police, and fire workers; utility and transportation workers; telecommunications and IT workers; funeral directors

People 7 to 12 years old and 41 to 50 years old with $<2$ high-risk conditions with priority as above

People 6 months to 6 years old and 51 to 64 years old with $<2$ high-risk conditions, with priority as above ${ }^{\ddagger}$

People $\geq 65$ years old with $<2$ high-risk conditions

3 Other health decision-makers in government Funeral directors
People with life-limiting morbidities or disabilities, prioritized according to expected life years
People 6 months to 64 years old with $\geq 2$ high-risk condition

People $\geq 65$ years old with $\geq 2$ high-risk conditions

* Tiers determine priority ranking for the distribution of vaccine if limited in supply. ISubtiers in purple text establish who gets priority within the tier (starting from the top of the tier) if limited vaccine cannot cover everyone in the tier: prioritization may occur within subtiers as well. $₹$ Children 6 months to $<13$ years would not receive vaccine if they can be effectively confined to home or otherwise isolated.

the stages of life is more appropriate for a pandemic $(8,9)$. There is great value in being able to pass through each life stage - to be a child, a young adult, and to then develop a career and family, and to grow old - and to enjoy a wide range of the opportunities during each stage.

Multiple considerations and intuitions support this ethical principle. Most people endorse this principle for themselves $(8,9)$. We would prioritize our own resources to ensure we could live past the illnesses of childhood and young adulthood and would allocate fewer resources to living ever longer once we reached old age (9). People strongly prefer maximizing the chance of living until a ripe old age, rather than being struck down as a young person $(10,11)$.

Death seems more tragic when a child or young adult dies than an elderly person - not because the lives of older people are less valuable, but because the younger person has not had the opportunity to live and develop through all stages of life. Although the life-cycle principle favors some ages, it is also intrinsically egalitarian (7). Unlike being productive or contributing to others' well-being, every person will live to be older unless their life is cut short.

\section{The Investment Refinement}

A pure version of the life-cycle principle would grant priority to 6-month-olds over 1-year-olds who have priority over 2-year-olds, and on. An alternative, the investment refinement, emphasizes gradations within a life span. It gives priority to people between early adolescence and middle age on the basis of the amount the person invested in his or her life balanced by the amount left to live (12). Within this framework, 20-yearolds are valued more than 1-year-olds because the older individuals have more developed interests, hopes, and plans but have not had an oppor- tunity to realize them $(11,12)$. Although these groupings could be modified, they indicate ethically defensible distinctions among groups that can inform rationing priorities.

One other ethical principle relevant for priority ranking of influenza vaccine during a pandemic is public order. It focuses on the value of ensuring safety and the provision of necessities, such as food and fuel. We believe the investment refinement combined with the public-order principle (IRPOP) should be the ultimate objective of all pandemic response measures, including priority ranking for vaccines and interventions to limit the course of the pandemic, such as closing schools and confining people to homes. These two principles should inform decisions at the start of an epidemic when the shape of the risk curves for morbidity and mortality are largely uncertain.

Like the NVAC and ACIP ranking, the IRPOP ranking would give high priority to vaccine production and distribution workers, as well as health-care and public health workers with direct patient contact. However, contrary to the NVAC and ACIP prioritization for the sick elderly and infants, IRPOP emphasize people between 13 and 40 years of age. The NVAC and ACIP priority ranking comports well with those groups at risk during the mildto-moderate 1957 and 1968 pandemics. IRPOP prioritizes those age cohorts at highest risk during the devastating 1918 pandemic. Depending on patterns of flu spread, some mathematical models suggest that following IRPOP priority ranking could save the most lives overall (13).

\section{Conclusions}

The life-cycle ranking is meant to apply to the situation in the United States. During a global pandemic, there will be fundamental questions about sharing vaccines and other interventions with other countries. This raises fundamental issues of global rationing that are too complex to address here.

Fortunately, even though we are worried about an influenza pandemic, it is not upon us. Indeed, the current $\mathrm{H} 5 \mathrm{~N} 1$ avian flu may never develop into a human pandemic. This gives us time both to build vaccine production capacity to minimize the need for rationing and to rationally assess policy and ethical issues about the distribution of vaccines.

\section{References and Notes}

1. U.S. Department of Health and Human Services (HHS), HHS Pandemic Influenza Plan (HHS, Washington, DC, 2005), supplement $E$ at (www.hhs.gov/pandemicflu/ plan/) (accessed 29 March 2006)

2. S. D. Collin, Public Health Rep. 60, 853 (1945).

3. D. R. Olson, L. Simonsen, P. J. Edelson, S. S. Morse, Proc. Natl. Acad. Sci. U.S.A. 102, 11059 (2005).

4. L. Simonsen et al., in The Threat of Pandemic Influenza: Are We Ready? S. L. Knobler et al., Eds. (National Academies Press, Washington, DC, 2004).

5. C. ]. L. Murray, A. D. Lopez, Eds., The Global Burden of Disease (World Health Organization, Geneva, 1996).

6. C. J. L. Murray, A. K. Acharya, J. Health Econ. 16, 710 (1997).

7. R. Dworkin, in Taking Rights Seriously (Harvard Univ. Press, Cambridge, MA, 1978), pp. 150-205.

8. A. Williams, Health Econ. 6, 117 (1997).

9. N. Daniels, in Am I My Parents' Keeper? (Oxford Univ. Press, New York, 1988), pp. 66-102.

10. M. L. Cropper, S. K. Aydede, P. R. Portney, J Risk Uncertainty 8, 243 (1994).

11. M. Johannesson, P. O. Johansson, J. Health Econ. 16, 589 (1997).

12. R. Dworkin, in Life's Dominion (Knopf, New York, 1993) pp.68-101.

13. M. E. Halloran, I. M. Longini Ir., Science 311, 615 (2006).

14. We thank A. Fauci, A. Friedman, B. Gellin, M. Gottesman, C. Grady, B. Krohmal, S. Pearson, B. Schwartz, L. Simonsen, and the Department of Clinical Bioethics. 